\title{
Mineração
}

\section{Regeneração natural em área degradada pela mineração de carvão em Santa Catarina, Brasil}

\author{
(Natural regeneration in an area degraded by \\ coal mining in Santa Catarina State, Brazil)
}

\section{Resumo}

O trabalho objetivou avaliar o grau de regeneração natural, em uma antiga área de mineração de carvão a céu aberto, passados 28 anos do término das atividades de extração do minério. A área de pesquisa está situada em Rio Carvão Alto, município de Urussanga, sul de Santa Catarina. Para o estudo foram selecionadas três zonas com aspectos geomorfológicos distintos. Para o estudo da regeneração natural das espécies arbustivo-arbóreas, foi utilizado o método de parcelas, sendo definidas três classes de altura. A amostragem da classe 1 de tamanho de planta $(0,20-0,50 \mathrm{~m}$ de altura), classe $2(0,51-1,50 \mathrm{~m}$ de altura) e classe $3(>1,5 \mathrm{~m}$ de altura $\mathrm{e}<5 \mathrm{~cm}$ de DAP) foi realizada em unidades de $1 \times 1,2 \times 2$ e $5 \times 5 \mathrm{~m}$, respectivamente. Foi estimada a regeneração das espécies, registrando-se, também, algumas características ecológicas. Foram amostradas 32 espécies. Destas, 50,0\% eram anemocóricas e 46,8\% zoocóricas, $51,7 \%$, pioneiras, $20,7 \%$, secundárias iniciais, $17,3 \%$ secundárias tardias e 10,3\%, climácicas. As espécies que apresentaram melhor desempenho na colonização e estruturação da regeneração natural foram Clethra scabra Pers., Myrsine coriacea (Sw.)R.Br. e Miconia cabucu Hoehne, sendo estas indicadas para uso nos programas de reabilitação de áreas mineradas em condições semelhantes.

Doutorando em Solos, UDESC

E-mail:alecsbio@yahoo.com.br

Vanilde Citadini-Zanette

Doutora em Ciências, Professora, UNESC

E-mail:vcz@unesc.net

\section{Rosana Peporine Lopes}

Doutora em Ciências, Geóloga E-mail:peporine@yahoo.com.br

\section{Robson dos Santos}

Doutorem Engenharia, Professor, UNESC E-mail:rsa@unesc.net

Palavras-chave: Mineração a céu aberto, vegetação espontânea, sucessão ecológica secundária, carvão mineral, estéreis de mineração, rejeitos da mineração.

\section{Abstract}

The present study aimed to study natural regeneration in an abandoned open-pit coal mining area, 28 years after the mining activities ceased. This research was carried out in Brazil, in the southern part of the State of Santa Catarina, Urussanga county, in Rio Carvão Alto. Three areas with different geomorphologic aspects were selected and for the study of natural regeneration of shrub and tree species, the plots method was used and three height classes were defined. The sampling unit sizes were $1 \times 1,2 \times 2$ e $5 x 5 \mathrm{~m}$, respectively, for class 1 plant size (height between 0.20 and $0.50 \mathrm{~m}$ ), class 2 (height between 0.51 and $1.50 \mathrm{~m}$ ) and class 3 (height $>1.5 \mathrm{~m}$ and $\mathrm{DBH}<5 \mathrm{~cm}$ ). Species regeneration was estimated, as well as the register of some ecological characteristics. A total of 32 species were sampled. Of the surveyed species, 50.0\% were anemochoric 
and $46.8 \%$ zoochoric, of these $51.7 \%$ were pioneer, $20.7 \%$ were early secondary, $17.3 \%$ were late secondary and $10.3 \%$ climax. Species that presented the best performance in colonization and structuring of natural regeneration were Clethra scabra, Myrsine coriacea e Miconia cabucu. These are indicated as promising species for rehabilitation programs of mined areas with similar conditions of successional strategy.

Keywords: Open pit mining, spontaneous vegetation, secondary ecological succession, coal mine, mining wastes.

\section{Introdução}

O processo de regeneração natural de uma espécie pode ser considerado como uma série de fases consecutivas, as quais afetam o seu êxito final. A fenologia, sua estratégia de polinização, sistema de cruzamento e dispersão de frutos e de sementes são fundamentais nesse processo (Negrelle, 2006). No entanto, a ocorrência de distúrbios naturais ou antrópicos criam habitates altamente heterogêneos no ambiente, proporcionando o recrutamento de diferentes espécies de plantas exibindo cenários diferentes de regeneração.

O entendimento de regeneração natural, segundo Volpato (1994), é possível por meio do estudo de fatores ambientais que afetam o crescimento e o desenvolvimento das plantas em regeneração, sendo a topografia do terreno um dos fatores que promovem variabilidade na estrutura da vegetação, principalmente pelo efeito de inclinação e exposição das encostas.

Nappo et alii (2000) salientam que a identificação e a mensuração de variáveis ambientais e do histórico da área são peças importantes para a compreensão dos processos de dinâmica de povoamentos e, em particular, para os ocorridos em áreas degradadas em fase de reabilitação por meio de revegetação e condução da regeneração natural.
Estudos sobre regeneração natural no sul de Santa Catarina foram realizados por Citadini-Zanette (1995) em um fragmento de Floresta Ombrófila Densa, submetido em épocas passadas a extração seletiva, mas que conservou sua biodiversidade; por Remor (2004) sob plantio de Mimosa scabrella Benth. (bracatinga), introduzida em blocos experimentais em áreas mineradas a céu aberto e por Citadini-Zanette e Boff (1992) e Santos et alii (2008), que abordaram a vegetação espontânea sobre pilhas de estéreis de mineração de carvão a céu aberto. Todos esses estudos visavam a subsidiar a recuperação de áreas degradadas pela mineração de carvão.

Os estudos básicos sobre sucessão em áreas que se encontram abandonadas depois de paralisado o processo de mineração são ferramentas adequadas a serem utilizadas para nortear estratégias para planejamento de recuperação de áreas mineradas (Barth, 1989;Citadini-Zanette \& Boff, 1992; Parrota et alii, 1997, Nunes, 2006; Santos et alii, 2008). No entanto, tais estudos abordando áreas degradadas por mineração de carvão e sua recuperação ainda são incipientes no Brasil (Santos, 2003, 2008). Dessa forma, o presente estudo teve como objetivos avaliar a regeneração natural em antropossolos originados pela mineração de carvão a céu aberto e caracterizar o substrato após 28 anos de término da explotação desse recurso mineral.

\section{Material e métodos}

A área de estudo está localizada no sul de Santa Catarina, no município de Urussanga, na localidade de Rio Carvão Alto (latitude 28 29'56" Sul e longitude 49²3'36" Oeste, altitude de 250m acima do nível do mar). O processo de extração mineral a céu aberto foi iniciado em 1968, perdurando até 1978. No total foram minerados $2.279 .500 \mathrm{~m}^{2}$ de área, tendo um volume de rochas removidas de $35.568 .586 \mathrm{~m}^{3}$, com produção de run of mine igual a 4.967.146t e de carvão prélavado igual a 1.537.421t (Müller et alii, 1987).

O antropossolo gerado no local de estudo (Figura 1) resulta da mistura dos horizontes do solo original com os estéreis (arenitos, siltitos e folhelhos) e rejeitos da mineração de carvão. Dessa atividade pretérita, foram originadas áreas com topografias distintas, pilhas com alturas e composições variadas, separadas por vales irregulares e estreitos. A partir de interpretação de fotografias aéreas coloridas (escala 1:5000), obtidas em aerolevantamento em 2006, foram selecionadas três zonas marcadamente distintas, capazes de representar a diversida-

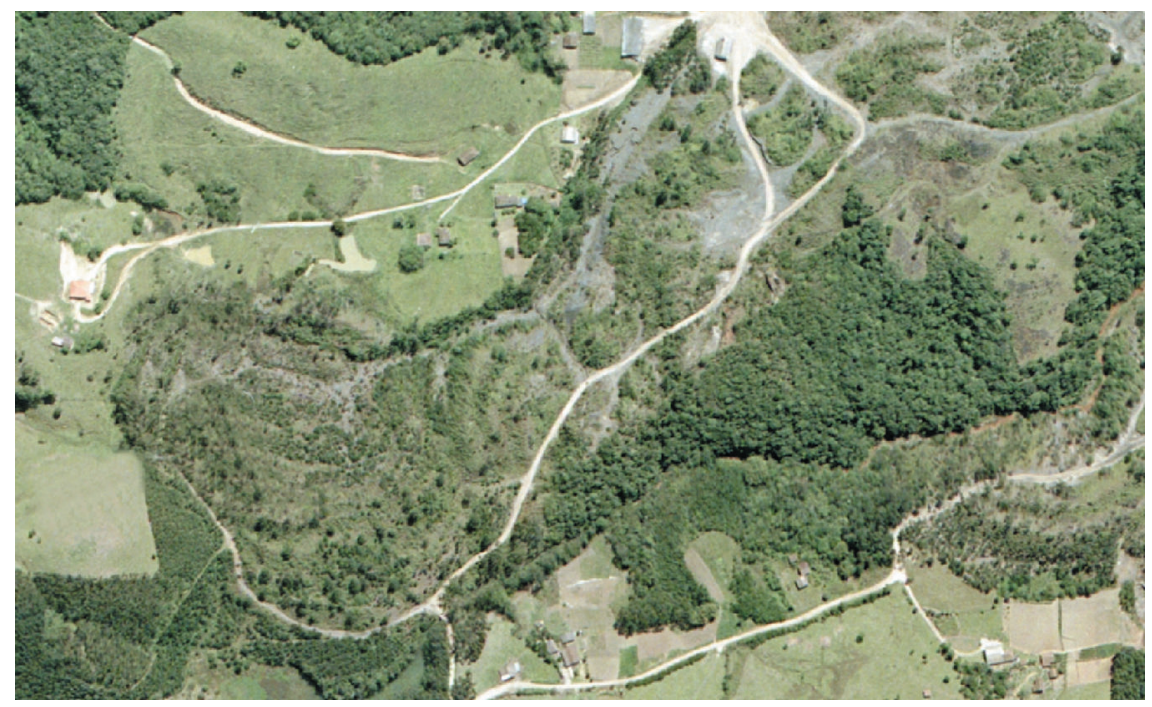

Figura 1 - Aspecto geral do local estudado na localidade de Rio Carvão Alto, município de Urussanga, Santa Catarina. 
Alecsandro Schardosim Klein et al.

de do local de pesquisa: 1) entre as pilhas de estéreis da mineração de carvão; 2) no topo das pilhas de estéreis da mineração e 3) em rejeitos de carvão mineral.

Para o estudo da regeneração natural das espécies arbustivo-arbóreas foi utilizado o método de parcelas (MuellerDombois \& Ellenberg, 1974). Pela metodologia empregada por Finol (1971), modificada por Volpato (1994), pode-se obter a estimativa da regeneração natural, dada pela expressão:

$\mathrm{RNC}_{\mathrm{ij}}=\frac{\mathrm{DR}_{\mathrm{ij}}+\mathrm{FR}_{\mathrm{ij}}}{2}$;

$\mathrm{RNT}_{\mathrm{i}}=\sum_{\mathrm{j}=1}^{\mathrm{z}} \mathrm{RNC}_{\mathrm{ij}}$

sendo: $\mathrm{RNC}_{\mathrm{ij}}=$ regeneração natural da i-ésima espécie na j-ésima classe de tamanho; $\mathrm{RNT}_{\mathrm{i}}=$ regeneração natural total da i-ésima espécie; $\mathrm{DR}_{\mathrm{ij}}=$ densidade relativa para a i-ésima espécie na j-ésima classe de tamanho; $\mathrm{FR}_{\mathrm{ij}}=$ freqüência relativa da i-ésima espécie na j-ésima classe de tamanho; e $\mathrm{Z}=$ número de classes de tamanho de planta.

Com base nessa metodologia, foram definidas três classes de altura: classe 1 (indivíduos com altura entre 0,20 e $0,50 \mathrm{~m}$ ); classe 2 (indivíduos com altura entre 0,51 e $1,50 \mathrm{~m}$ ) e classe 3 (indivíduos com altura maior de $1,50 \mathrm{~m}$ e com diâmetro a $1,30 \mathrm{~m}$ do solo -DAP- menor que $5 \mathrm{~cm})$. Os indivíduos da classe 1 foram amostrados em 30 parcelas de $1 \times 1 \mathrm{~m}$ $\left(30 \mathrm{~m}^{2}\right)$, da classe 2 , em 30 parcelas de $2 \times 2 \mathrm{~m}\left(120 \mathrm{~m}^{2}\right)$ e da classe 3 , em 30 parcelas de $5 \times 5 \mathrm{~m}\left(750 \mathrm{~m}^{2}\right)$, em cada uma das três zonas consideradas.

A caracterização dos substratos das três zonas amostradas foi realizada a partir do reconhecimento dos tipos de materiais rochosos, granulometria e do tipo de antropossolo em desenvolvimento ou gerado. Seguindo metodologia da Embrapa (1988), foram coletadas amostras do antropossolo utilizando-se trado holandês, ao longo de cada zona, em in- tervalos regulares e profundidades de 20 $\mathrm{cm}$, para posterior análise. Foram coletadas 10 amostras em cada uma das três zonas. Misturaram-se as amostras até a homogeneização, constituindo uma única amostra representativa para cada zona, sendo que tais amostras foram, posteriormente, encaminhadas ao laboratório da Companhia Integrada de Desenvolvimento Agrícola de Santa Catarina (CIDASC) para análises químicas e texturais. A interpretação dos resultados foi feita conforme recomendações de adubação e calagem para os estados do Rio Grande do Sul e de Santa Catarina (Comissão de Fertilidade do Solo-RS/SC, 1994).

As espécies amostradas foram enquadradas em grupos ecológicos (categorias sucessionais), segundo os procedimentos de Ferreti et alii (1995), que identificam quatro grupos de espécies: pioneiras, secundárias iniciais, secundárias tardias e climácicas. Consideram-se os aspectos relacionados com as estratégias de dispersão das espécies, seguindo princípios de van der Pijl (1972).

O material vegetal coletado foi incorporado ao acervo do Herbário Pe. Dr. Raulino Reitz (CRI) da Universidade do Extremo Sul Catarinense (UNESC). A identificação foi feita através de comparações com o material do referido herbário, consultas à literatura pertinente e com o auxílio de especialistas.

\section{Resultados}

O solo da área estudada, antes da extração do carvão mineral que descaracterizou suas camadas, era classifica-

Tabela 1 - Resultado das análises químicas e texturais dos substratos amostrados em Rio Carvão Alto, município de Urussanga, SC. Onde: $\mathrm{MB}=$ muito baixo; $\mathrm{B}=$ baixo; $\mathrm{M}=$ médio; $\mathrm{MA}$ = muito alto; Res = resultado e Ref = referência

\begin{tabular}{c|c|c|c|c|c|c}
\hline \multirow{2}{*}{ Parâmetro } & \multicolumn{2}{|c|}{ Zona 1 } & \multicolumn{2}{c|}{ Zona 2 } & \multicolumn{2}{c}{ Zona 3 } \\
\cline { 2 - 7 } & Res & Ref & Res & Ref & Res & Ref \\
\hline Classe textural III (\%) & 38 & & 32 & & 38 & \\
\hline $\mathrm{pH}$ & 4,1 & $\mathrm{MB}$ & 3,5 & $\mathrm{MB}$ & 4,3 & $\mathrm{MB}$ \\
\hline Índice SMP & 4,0 & & 4,0 & & 4,3 & \\
\hline $\mathrm{P}(\mathrm{ppm})$ & 8,3 & $\mathrm{M}$ & 5,3 & $\mathrm{~B}$ & 8,9 & $\mathrm{M}$ \\
\hline $\mathrm{K}(\mathrm{ppm})$ & 128,0 & & 78,0 & & 131,0 & \\
\hline Matéria Orgânica $(\%)$ & 2,8 & $\mathrm{M}$ & 1,9 & $\mathrm{~B}$ & 0,7 & $\mathrm{~B}$ \\
\hline $\mathrm{Al}(\mathrm{cmolc} / \mathrm{L})$ & 9,4 & & 7,7 & & 10,8 & \\
\hline $\mathrm{Ca}(\mathrm{cmolc} / \mathrm{L})$ & 1,4 & $\mathrm{~B}$ & 1,6 & $\mathrm{~B}$ & 0,7 & $\mathrm{~B}$ \\
\hline $\mathrm{Mg} \mathrm{cmolc/L}$ & 1,0 & $\mathrm{M}$ & 0,4 & $\mathrm{~B}$ & 1,5 & $\mathrm{~A}$ \\
\hline $\mathrm{Na}(\mathrm{ppm})$ & 11,0 & & 9,0 & & 10,0 & \\
\hline $\mathrm{H}+\mathrm{Al}(\mathrm{cmolc} / \mathrm{L})$ & 43,3 & & 43,3 & & 30,7 & \\
\hline $\mathrm{pH} \mathrm{CaCl} 2$ & 3,6 & $\mathrm{MA}$ & 3,2 & $\mathrm{MA}$ & 3,6 & $\mathrm{MA}$ \\
\hline $\mathrm{S}(\mathrm{cmolc} / \mathrm{L})$ & 2,8 & $\mathrm{M}$ & 2,2 & $\mathrm{~B}$ & 2,6 & $\mathrm{~B}$ \\
\hline $\mathrm{CTC} \mathrm{cmolc} / \mathrm{L}$ & 46,1 & $\mathrm{~A}$ & 45,6 & $\mathrm{~A}$ & 33,3 & $\mathrm{~A}$ \\
\hline $\mathrm{V}(\%)$ & 6,0 & $\mathrm{MB}$ & 4,9 & $\mathrm{MB}$ & 7,7 & $\mathrm{MB}$ \\
\hline
\end{tabular}


Regeneração natural em área degradada pela mineração de carvão em Santa Catarina, Brasil

do como associação de Cambissolos Háplicos + Argissolos Amarelos (Dufloth et alii, 2005), restando, atualmente, apenas vestígios na base das pilhas de estéreis da mineração de carvão.

Os resultados das análises dos substratos se encontram na Tabela 1 . Nota-se que as diferenças mais significativas estão nos teores de K e na matéria orgânica.

Quanto à vegetação arbustivo-arbórea encontrada, a zona 1 (entre pilhas de estéreis) apresentou o maior número de espécies (25 ou $30 \%$ do to- tal), seguida da zona 2 (topo das pilhas de estéreis) com 16 espécies $(20 \%)$ e da zona 3 (rejeito de beneficiamento) com 12 espécies (15\%).

Os maiores valores para a regeneração natural na maior classe de altura $(>1,50 \mathrm{~m})$ evidenciam a substituição das espécies no processo sucessional (Tabelas 2 a 4 ).

Em todas as três zonas amostradas o grupo das pioneiras foi predominante (Figura 2), seguido pelas secundárias iniciais, secundárias tardias e climácicas, mostrando, claramente, que a comunida- de é jovem e encontra-se em franco processo de ocupação da área. $\mathrm{Na}$ zona 1 , espécies pertencentes aos grupos iniciais de sucessão perfazem $70,8 \%$ do total das espécies, na zona $2,84,6 \%$, e na zona 3, $90,0 \%$.

As espécies encontradas nas três zonas, quanto à dispersão de seus propágulos, foram categorizadas como zoocóricas, anemocóricas e autocóricas (Figura 3). Na zona 1, predominou a zoocoria, enquanto que, nas zonas 2 e 3, foi a anemocoria. A dispersão autocórica foi incipiente (uma espécie na zona 1 e outra na zona 3 ).

Tabela 2 - Índices de regeneração natural da vegetação localizada entre as pilhas de estéreis da mineração (zona 1), onde GE = grupo ecológico (Pio = pioneiras, $\operatorname{Sin}$ = secundária inicial, Sta = secundária tardia; Cli = clímax); Disp = estratégias de dispersão (Ane = anemocórica, Zoo = zoocórica, Aut = autocórica); RNC1, RNC2, RNC3 = classes de regeneração natural; RNT = regeneração natural total.

\begin{tabular}{|c|c|c|c|c|c|c|}
\hline \multirow{2}{*}{ Espécie } & \multirow{2}{*}{ GE } & \multirow{2}{*}{ Disp } & \multicolumn{4}{|c|}{ Regeneração Natural } \\
\hline & & & RNC1 & RNC2 & RNC3 & RNT \\
\hline Clethra scabra Pers. & Pio & Ane & 0,5 & 8,3 & 15,5 & 24,3 \\
\hline Myrsine coriacea (Sw.) R.Br. & $\operatorname{Sin}$ & Zoo & 1,6 & 5,3 & 13,9 & 20,8 \\
\hline Miconia cabucu Hoehne & Pio & Zoo & 1,6 & 1,1 & 5,4 & 8,0 \\
\hline Eupatorium vauthierianum DC. & Pio & Ane & 1,1 & 0,5 & 5,9 & 7,5 \\
\hline Eucalyptus saligna Sm. ${ }^{*}$ & - & - & 0,0 & 1,6 & 5,9 & 7,5 \\
\hline Tibouchina sellowiana Cogn. & $\operatorname{Sin}$ & Ane & 0,0 & 3,5 & 3,2 & 6,7 \\
\hline Tibouchina ramboi Brade & $\operatorname{Sin}$ & Ane & 0,0 & 1,1 & 4,3 & 5,4 \\
\hline Piptocarpha tomentosa Baker & Pio & Ane & 0,5 & 0,5 & 2,7 & 3,8 \\
\hline Clusia parviflora (Sald.) Engl. & Sta & Zoo & 1,1 & 0,5 & 1,6 & 3,2 \\
\hline Vernonia discolor (Spreng.) Lees. & Pio & Ane & 0,0 & 0,5 & 2,1 & 2,7 \\
\hline Eupatorium intermedium DC. & Pio & Ane & 0,0 & 1,6 & 0,0 & 1,6 \\
\hline Matayba guianensis Aubl. & Pio & Zoo & 0,0 & 1,1 & 0,0 & 1,1 \\
\hline Cabralea canjerana (Vell.) Mart. & Sta & Zoo & 0,5 & 0,5 & 0,0 & 1,1 \\
\hline Xylopia brasiliensis Spreng. & Sta & Zoo & 0,0 & 0,5 & 0,0 & 0,5 \\
\hline Symplocos tenuifolia Brand & Pio & Aut & 0,0 & 0,5 & 0,0 & 0,5 \\
\hline Pisidium cattleianum Sabine & Sta & Zoo & 0,0 & 0,5 & 0,0 & 0,5 \\
\hline Piper gaudichaudianum Kunth & Sin & Zoo & 0,0 & 0,5 & 0,0 & 0,5 \\
\hline Nectandra oppositifolia Nees et Mart. & Sta & Zoo & 0,0 & 0,5 & 0,0 & 0,5 \\
\hline Nectandra membranacea (Sw.) Griseb. & $\mathrm{Cli}$ & Zoo & 0,0 & 0,5 & 0,0 & 0,5 \\
\hline Jacaranda puberula Cham. & Pio & Ane & 0,0 & 0,0 & 0,5 & 0,5 \\
\hline Euterpe edulis Mart. & $\mathrm{Cli}$ & Zoo & 0,5 & 0,0 & 0,0 & 0,5 \\
\hline Casearia sylvestris Sw. & $\operatorname{Sin}$ & Zoo & 0,0 & 0,0 & 0,5 & 0,5 \\
\hline Baccharis brachylaenoides DC. & Pio & Ane & 0,0 & 0,0 & 0,5 & 0,5 \\
\hline Alchornea triplinervia (Spreng.) Müll.Arg. & $\operatorname{Sin}$ & Zoo & 0,0 & 0,5 & 0,0 & 0,5 \\
\hline Achyrocline satureoides (Lam.) DC. & Pio & Ane & 0,5 & 0,0 & 0,0 & 0,5 \\
\hline Total & & & 8,0 & 29,9 & 62,1 & 100 \\
\hline
\end{tabular}

*Espécie exótica, pioneira, com dispersão anemocórica. 
Alecsandro Schardosim Klein et al.

Tabela 3 - Índices de regeneração natural da vegetação localizada no topo das pilhas de estéreis da mineração (zona 2), onde $\mathrm{GE}=$ grupo ecológico ( $\mathrm{Pio}=$ pioneiras, $\mathrm{Sin}=$ secundária inicial, $\mathrm{Sta}=$ secundária tardia; $\mathrm{Cli}=$ clímax $)$; Disp = estratégias de dispersão (Ane = anemocórica, Zoo = zoocórica, Aut = autocórica); RNC1, RNC2, RNC3 = classes de regeneração natural; RNT = regeneração natural total.

\begin{tabular}{c|c|c|c|c|c|c}
\hline Espécie & \multirow{2}{*}{ GE } & \multirow{2}{*}{ Disp } & \multicolumn{4}{|c}{ Regeneração Natural } \\
\cline { 5 - 7 } & & & RNC1 & RNC2 & RNC3 & RNT \\
\hline Myrsine coriacea (Sw.) R.Br. & Sin & Zoo & 4,6 & 11,5 & 13,0 & 29,0 \\
\hline Clethra scabra Pers. & Pio & Ane & 3,1 & 10,7 & 10,5 & 24,2 \\
\hline Eucalyptus saligna Sm. ${ }^{*}$ & - & - & 0,6 & 5,1 & 16,3 & 22,0 \\
\hline Tibouchina ramboi Brade & Sin & Ane & 0,6 & 1,8 & 3,1 & 5,5 \\
\hline Clusia parviflora (Sald.) Engl. & Sta & Zoo & 1,8 & 3,1 & 0,6 & 5,5 \\
\hline Tibouchina sellowiana Cogn. & Sin & Ane & 0,6 & 2,5 & 0,0 & 3,1 \\
\hline Eupatorium intermedium DC. & Pio & Ane & 0,0 & 1,8 & 1,2 & 3,1 \\
\hline Laplacea acutifolia (Wawra) Kobuski $_{\text {Tibouchina urvilleana Cogn. }}$ & Pio & Zoo & 0,0 & 0,9 & 1,2 & 2,1 \\
\hline Pisidium cattleianum Sabine & Pio & Ane & 0,0 & 0,6 & 0,0 & 0,6 \\
\hline Pinus elliottii Engelm. ${ }^{*}$ & Sta & Zoo & 0,0 & 0,6 & 0,0 & 0,6 \\
\hline Eupatorium vauthierianum DC. & - & - & 0,0 & 0,6 & 0,0 & 0,6 \\
\hline Eupatorium sp. & Pio & Ane & 0,0 & 0,0 & 0,6 & 0,6 \\
\hline Eucalyptus citriodora Hook. ${ }^{*}$ & Pio & Ane & 0,0 & 0,0 & 0,6 & 0,6 \\
\hline Baccharis dracunculifolia DC. & - & - & 0,0 & 0,0 & 0,6 & 0,6 \\
\hline Alchornea triplinervia (Spreng.) Müll.Arg. & Pio & Ane & 0,0 & 0,0 & 0,6 & 0,6 \\
\hline Total & Zoo & 0,6 & 0,0 & 0,0 & 0,6 \\
\hline
\end{tabular}

*Espécie exótica, pioneira, com dispersão anemocórica.

Tabela 4 - Índices de regeneração natural da vegetação localizada em contato direto com rejeitos do beneficiamento do carvão mineral (zona 3), onde GE = grupo ecológico (Pio = pioneiras, Sin = secundária inicial, Sta = secundária tardia; Cli = clímax); Disp = estratégias de dispersão (Ane $=$ anemocórica, Zoo = zoocórica, Aut = autocórica); RNC1, RNC2, RNC3 = classes de regeneração natural; RNT = regeneração natural total.

\begin{tabular}{c|c|c|c|c|c|c}
\hline Espécie & \multirow{2}{*}{ GE } & \multirow{2}{*}{ Disp } & \multicolumn{4}{|c}{ Regeneração Natural } \\
\cline { 4 - 7 } & & & RNC1 & RNC2 & RNC3 & RNT \\
\hline Eucalyptus saligna Sm. ${ }^{*}$ & & & 2,9 & 14,1 & 36,0 & 53,0 \\
\hline Myrsine coriacea (Sw.) R.Br. & Sin & Zoo & 3,8 & 7,9 & 11,1 & 22,8 \\
\hline Eupatorium vauthierianum DC. & Pio & Ane & 0,0 & 3,3 & 3,8 & 7,1 \\
\hline Clethra scabra Pers. & Pio & Ane & 1,3 & 0,0 & 2,9 & 4,2 \\
\hline Eucalyptus citriodora Hook. ${ }^{*}$ & - & - & 0,0 & 0,0 & 2,9 & 2,9 \\
\hline Symplocos tenuifolia Brand & Pio & Aut & 0,0 & 1,3 & 1,3 & 2,5 \\
\hline Vernonia discolor (Spreng.) Less. & Pio & Ane & 1,3 & 0,0 & 0,0 & 1,3 \\
\hline Tibouchina sellowiana Cogn. & Sin & Ane & 0,0 & 0,0 & 1,3 & 1,3 \\
\hline Piptocarpha tomentosa Baker & Pio & Ane & 0,0 & 0,0 & 1,3 & 1,3 \\
\hline Miconia cabucu Hoehne & Pio & Zoo & 1,3 & 0,0 & 0,0 & 1,3 \\
\hline Ocotea puberula Nees & Cli & Zoo & 0,0 & 1,3 & 0,0 & 1,3 \\
\hline Alchornea triplinervia (Spreng.) Müll.Arg. & Sin & Zoo & 0,0 & 0,0 & 1,3 & 1,3 \\
\hline Total & & & 10,4 & 27,8 & 61,7 & 100 \\
\hline
\end{tabular}

`Espécie exótica, pioneira, com dispersão anemocórica. 


\section{Discussão}

Segundo Dias (1998), a faixa ideal de $\mathrm{pH}$, para a nutrição das plantas, situa-se entre 5,6 e 6,2, quando a maioria dos nutrientes se encontra na forma solúvel, facilmente absorvido pelas raízes. $\mathrm{Na}$ área de estudo, as espécies vegetais estão se desenvolvendo em substrato com pH muito ácido (entre 3,5 e 4,3) e com teores de matéria orgânica muito baixos (entre $0,7 \%$ e $3,7 \%$ ). Tal fato sugere que essas espécies têm a capacidade de se adaptarem às condições extremas, podendo, portanto, serem utilizadas na recuperação de áreas degradadas pela mineração de carvão a céu aberto.

Nas três zonas amostradas, o $\mathrm{pH}$ baixo do substrato resulta da alta concentração de íons $\mathrm{H}^{+}$e poucos íons de cálcio, magnésio, potássio e sódio adsorvidos em seus complexos de troca, o que é evidenciado pela saturação de bases, que variou entre $4,9 \%$ e $7,7 \%$ da capacidade de troca de cátions.

As áreas com topografia irregular, como observadas nas zonas 1 e 2 , apresentaram maior número de espécies e de indivíduos. Segundo Regensburger (2004), nessa condição, a temperatura do solo e do ar é amenizada devido ao menor tempo de exposição direta ao espectro eletromagnético por unidade de área e pelo processo de difusão da luz, mantendo tal espectro numa faixa mais constante e propício ao metabolismo das plantas. Aumond (2003) ressalta que, numa superfície irregular, os raios luminosos sofrem reflexão difusa pela manhã e à tarde, diminuindo, pontualmente, o nível de intensidade luminosa, proporcionando produção primária (fotossíntese) mais eficiente, já que esse processo requer, geralmente, uma condição de luz pouco intensa.

Aumond (2003) relata, ainda, que a desorganização espacial das áreas degradadas, por meio de rugosidades, cria superfícies convexas (dissipadoras) adjacentes às superfícies côncavas (concentradoras) e, com isso, obtém-se aumento da superfície total da área, iniciando o movimento vertical e horizontal

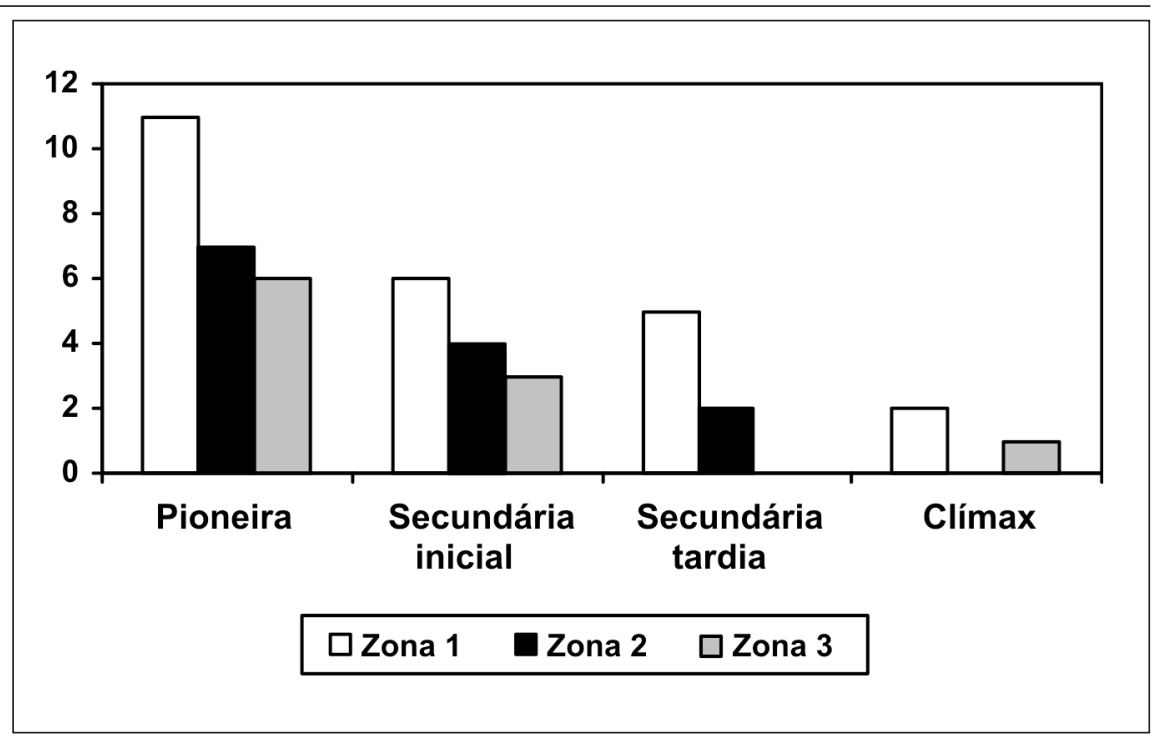

Figura 2 - Agrupamento das espécies vegetais nativas em grupos ecológicos em área degradada pela mineração de carvão a céu aberto, Urussanga, SC.

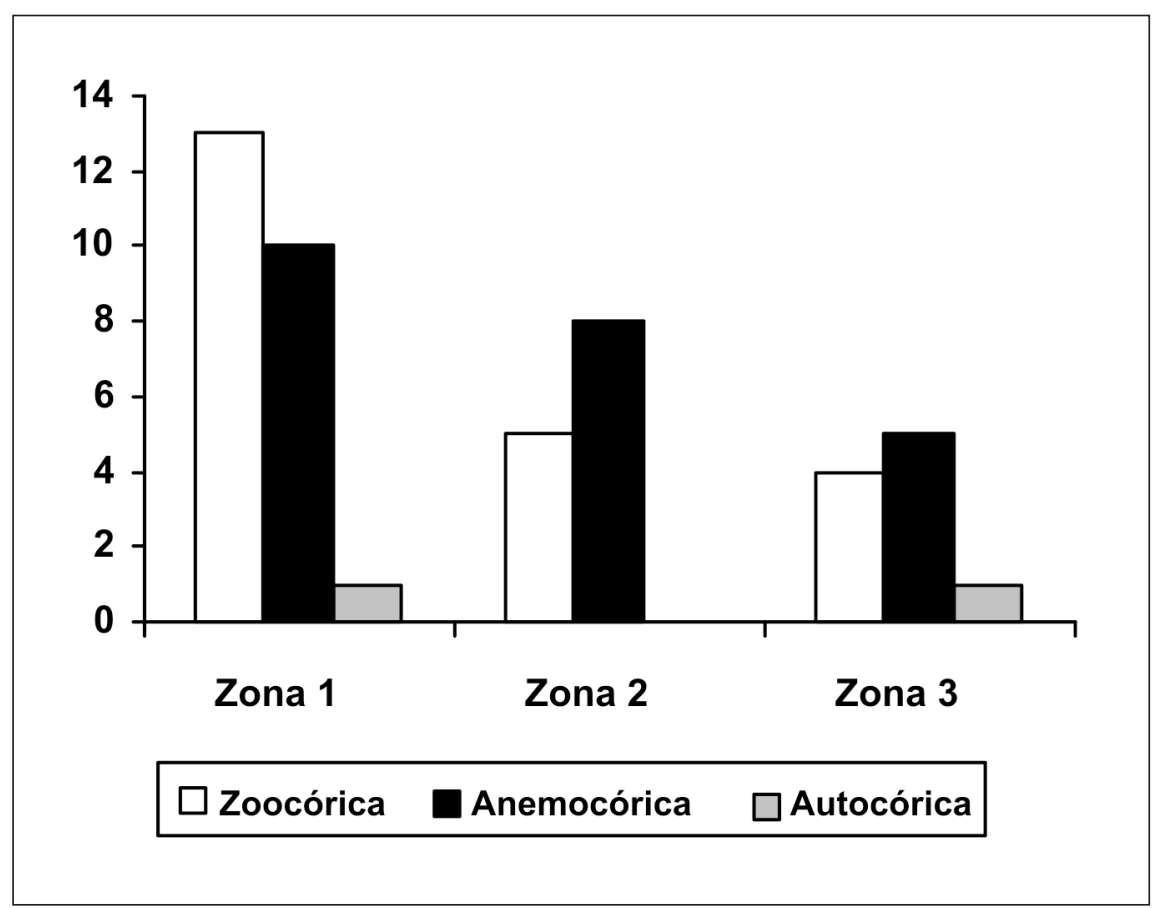

Figura 3 - Agrupamento das espécies vegetais nativas em estratégias de dispersão em área degradada pela mineração de carvão, Urussanga, SC.

da água, erosão e lixiviação de sedimentos, resíduos orgânicos e colóides, que irão se depositar internamente nas depressões do terreno, além de aumentar a superfície de contato com oxigênio, dióxido de carbono e exposição à radiação solar.

Por apresentar rejeito de mineração, praticamente sem solo em desenvolvi- mento, e ser relativamente plana, a zona 3 , apresentou menor número de espécies. Tal fato parece estar mais relacionado com a maior radiação luminosa, superaquecimento do substrato e baixo acúmulo de material orgânico e de umidade.

As cinco espécies com maior regeneração natural total (RNT) foram classificadas como pioneiras, apresentando, 
segundo Ferreti et alii (1995), necessidade de luz direta para germinação das sementes, crescimento e desenvolvimento. São plantas com crescimento rápido e ciclo de vida curto, florescimento precoce, frutos e sementes pequenas com viabilidade longa, geralmente dispersos pelo vento.

Algumas espécies cujas populações estão presentes somente nas classes RNC2 e RNC3 de altura (Alchornea triplinervia, Eupatorium vauthierianum, E. intermedium, Laplacea acutifolia, Symplocos tenuifolia, Tibouchina sellowiana e Vernonia discolor), consideradas pioneiras, podem ter dificuldade inicial de estabelecimento, quando a comunidade já está em processo mais adiantado de sucessão secundária ou pela maior seletividade a que estão expostas.Já as espécies que estão presentes apenas na classe de menor altura (RNC1) e com poucos indivíduos, como é o caso de Euterpe edulis, pode indicar sua dificuldade em se estabelecer no local, por pertencer à categoria sucessional mais avançada (clímax).

A concentração de indivíduos e de espécies nos estádios iniciais de sucessão (pioneiras + secundárias iniciais) sinaliza que a comunidade estudada se encontra em etapa seral pioneira. O predomínio de espécies pioneiras vem confirmar algumas das características mais marcantes desse grupo ecológico, como o rápido crescimento e o ciclo de vida curto (Ferreti et alii, 1995). No entanto, o sombreamento proporcionado pelo dossel já está possibilitando a regeneração de espécies de etapas serais mais avançadas, como Clusia parviflora, Cabralea canjerana, Pisidium cattleianum, Nectandra oppositifolia e N. membranacea.

A regeneração natural mais efetiva ocorreu na zona 1 , mesmo com a área apresentando alterações em suas características bióticas e edáficas. $\mathrm{O}$ avanço da regeneração natural, nessa zona, pode ser atribuído a um conjunto de fatores e suas interações, que foram decisivos para a dinâmica da área. Fragmentos florestais remanescentes próximos funcionam como local de abrigo à fauna dispersora, principalmente pássaros, que, durante o deslocamento entre os fragmentos, podem contribuir para a ocupação vegetal nessas áreas (Gandolfi \& Rodrigues, 2007). Adicionalmente, devese considerar a existência de maior acúmulo de serapilheira na zona 1, que mantém o solo mais úmido e, conseqüentemente, favorece maior riqueza específica. No entanto, a proximidade de fontes de diásporos apesar de fator-chave para o processo de colonização vegetal (Rodrigues et alli, 2004) não foi determinante para a regeneração natural nas zonas 2 e 3 . Nesses ambientes mais críti$\cos$, as plantas estão sujeitas a interações de múltiplos fatores estressantes, nem sempre possível de serem avaliadas.

Na zona 2, a morfologia do terreno, favorecendo a lixiviação do substrato, a presença de matacões e a baixa disponibilidade de água, provavelmente, dificultaram a regeneração natural, fato comprovado pela presença de Clethra scabra, espécie pioneira, freqüentemente encontrada nos solos pobres ou compactados, de vegetação mais esparsa e menos desenvolvida (Ichaso \& Guimarães, 1975), espécie recomendada para plantio puro ou misto a pleno sol (Carvalho, 2006).

Na zona 3, os rejeitos do beneficiamento do carvão mineral dificultaram a chegada da vegetação, obtendo mais sucesso Eucalyptus saligna, espécie exótica, que apresentou RNT = 53,0\%.

A chegada das espécies, nas três zonas, pode ser também atribuída a processos estocásticos, associados a diferentes características biológicas das espécies, e tal chegada pode gerar mudanças significativas nas comunidades ao longo do tempo, como relatado por Hubell e Foster (1986) para árvores de florestas tropicais. Por outro lado, o sucesso da regeneração natural é dependente de fatores relacionados à biologia reprodutiva de cada espécie, englobando, desde estratégias de polinização, até dispersão dos frutos e sementes. Estas, quando dispersas, devem encontrar, no local, condições de luz, temperatura e umidade adequadas para sua germinação. E a ocorrência de distúrbios ou áreas impactadas cria ambientes altamente heterogêneos com ocorrência de espécies com diferentes exigências ecológicas, como verificado na área em estudo.

A dispersão de sementes constitui um dos mecanismos essenciais para a dinâmica das florestas e, conseqüentemente, influenciam na regeneração natural das populações (Tabarelli \& Peres, 2002).

A fauna se mostrou importante dispersor de propágulos nas três zonas, muito embora o vento tenha contribuído com relevância como dispersor para as zonas 2 e 3. Para espécies cuja dispersão de propágulos é zoocórica, as limitações para a dispersão são maiores que para aquelas dispersas pelo vento (anemocóricas), pois os animais dispersores podem estar ausentes ou em baixo número na área, principalmente em função da fragmentação de habitates (Scariot et alii, 2003), em que se prevê perda significativa de espécies quanto menor a área e maior o seu isolamento.

\section{Conclusão}

Esse estudo permitiu verificar quais espécies podem desenvolver-se em áreas degradadas pela mineração de carvão, servindo como suporte para estudos de recuperação ambiental no sul de Santa Catarina. Outrossim, possibilitou identificar fatores responsáveis pela facilitação da regeneração natural nessa área.

Observou-se, nas diferentes zonas, que o desenvolvimento das espécies é fortemente influenciado pelas características que o local oferece e que pequenas alterações, nesse local, podem provocar grande variação de resposta no crescimento dessas espécies.

A localização da zona 1 , entre as pilhas de estéreis de mineração, possibilitou temperatura mais amena, maior acúmulo de matéria orgânica e maior umidade, resultando em maior número de espécies e de indivíduos.

As espécies nativas mais adaptadas a esse tipo de ambiente, consideran- 
do-se que estão presentes em todas as classes de regeneração natural, e que podem ser recomendadas para recuperação de áreas degradadas pela mineração de carvão a céu aberto são Clethra scabra, Myrsine coriacea, Miconia cabucu.

As espécies acima e Eucalyptus saligna, espécie exótica introduzida na área, foram encontradas em todas as zonas estudadas, variando apenas no número de indivíduos por local, indicando que são capazes de desenvolverem em diferentes tipos de substrato, mesmo que haja variações significativas de granulometria, $\mathrm{pH}$ e nutrientes. Essas espécies destacaram-se das demais encontradas, nos valores dos parâmetros fitossociológicos e de regeneração natural.

Sugere-se a continuidade dessa pesquisa, visando a estudos de média e longa duração, que poderão responder com dados mais concretos sobre as trajetórias dos processos sucessionais que ocorrem em áreas degradadas pela mineração de carvão.

\section{Referências bibliográficas}

AUMOND, J. J. Teoria dos Sistemas: uma nova abordagem para recuperação e restauração ambiental. In: SIMPOSIO BRASILEIRO DE ENGENHARIA AMBIENTAL, 2, 2003, Itajaí. Anais... Itajaí: UNIVALI, 2003. p. 10-6.

BARTH, R. C. Avaliação da recuperação de áreas mineradas no Brasil. Viçosa: UFV, 1989.

CARVALHO, P. E. R. Espécies arbóreas brasileiras. Brasília: Embrapa Informação Tecnológica, 2006. 627p.

CITADINI-ZANETTE, V. Florística, fitossociologia e aspectos da dinâmica de um remanescente de mata atlântica na microbacia do rio Novo, Orleans, SC. São Carlos: Universidade Federal de São Carlos, 1995. 249f. (Tese de Doutorado em Ecologia e Recursos Naturais).

CITADINI-ZANETTE, V., BOFF, V. P. Levantamento florístico em áreas mineradas a céu aberto na região carbonífera de Santa Catarina, Brasil. Florianópolis: SDM/FEPEMA, 1992. $160 \mathrm{p}$.
COMISSÃO DE FERTILIDADE DO SOLO - RS/SC. Recomendações de adubação e de calagem para os estados do Rio Grande do Sul e Santa Catarina. 3. ed. Passo Fundo: SBCS, 1994. 22p.

DIAS, L. E. Caracterização de substratos para fins de recuperação de áreas degradadas. In: DIAS, L.E., MELLO, J.W.V. Recuperação de áreas Degradadas. Viçosa: UFV/SOBRADE, 1998. p. 27-44.

DUFLOTH, J. H. et alii (Org). Estudos básicos regionais de Santa Catarina. Florianópolis: Epagri, 2005. CD-ROM.

FERRETTI, A. R. et alii. Classificação das espécies arbóreas em grupos ecológicos para revegetação com nativas no Estado de São Paulo. Florestar Estatístico, São Paulo, v. 3, n. 7, p. 73-77, 1995.

FINOL, U. H. Nuevos parametros a considerarse en el analisis estrutural de las selvas virgenes tropicales. Revista Forestal Venezolana, v. 18, n. 12, p. 29-42, 1971.

GANDOLFI, S., RODRIGUES, R. R. Metodologias de restauração florestal. In: FUNDAÇÃO CARGILL (Coord.) Manejo ambiental e restauração de áreas degradadas. São Paulo: Fundação Cargill, 2007. p. 109-43.

HUBBell, S. P., FOSTER, R. B. Commonness and rarity in a neotropical forest: implications for tropical tree conservation. In: SOULE, M.E. Conservation biology: The science of scarcity and diversity. Sunderland: Sinauer Associate, 1986. p. 205-231.

ICHASO, C. L. F., GUIMARÃES, E. F. Cletráceas. In: REITZ, P. R. (Ed.). Flora ilustrada catarinense. Itajaí: Herbário Barbosa Rodrigues, 1975. 19p.

MUELLER-DOMBOIS, D. \& ELLENBERG, $\mathrm{H}$. Aims and methods of vegetation ecology. New York: Wiley, 1974. 547p.

MÜller, A. A. et alii. Perfil analítico do carvão. 2. ed. Porto Alegre: DNPM, 1987. $140 \mathrm{p}$.

NAPPO, M. E. et alii. A estrutura do subbosque de povoamentos homogêneos de Mimosa Scabrella Bentham, em área minerada, em Poços de Caldas, MG, Brasil. Ciência Florestal, Santa Maria, v. 10, n. 2, p. 17-29, 2000.

NEGRELLE, R.R.B. Composição e estrutura vertical de um trecho de Floresta Ombrófila Densa de Planície Quaternária. Hoehnea, São Paulo, v. 33, n. 3, p. 261-289, 2006.

NUNES, M. F. S. Q. C O papel da regeneração natural na recuperação de áreas degradadas. In: GARAY, I., BECKER, B.K. (Org.) Dimensĩes humanas da biodiversidade. Petrópolis: Vozes, 2006. p. 3341-3351.
PARROTA, J. A. et alii. Development of floristic diversity in 10-year-old restoration Forest on a bauxite mined site in Amazônia. Forest Ecology and Management, v. 99, p. 21-42, 1997.

REGENSBURGER, R. Recuperação de áreas degradadas pela mineração de argila através da regularização topográfica, da adição de insumos e serrapilheira e de atratores da fauna. Florianópolis: Universidade Federal de Santa Catarina, 2004. 99f. (Dissertação de Mestrado em Agroecossistemas).

REMOR, R. Regeneração natural em blocos experimentais de Mimosa Scabrella Benth. (Bracatinga): subsídios para recuperação de áreas degradadas pela mineração de carvão a céu aberto no sul do Estado de Santa Catarina, Brasil. Criciúma: Universidade do Extremo Sul Catarinense, 2004. 109f. (Dissertação de Mestrado em Ciências Ambientais).

RODRIGUES, R. R. et alii. Tropical rain Forest regeneration in area degraded by mining in Mato Grosso State, Brazil. Forest Ecology and Management, v. 190, p. 323-333, 2004.

SANTOS, R. Reabilitação de ecossistemas degradados pela mineração de carvão a céu aberto em Santa Catarina, Brasil. São Paulo: Universidade de São Paulo, 2003. 115f. (Tese de Doutorado em Engenharia).

SANTOS et alii. Spontaneous vegetation on overburden piles in the coal basin of Santa Catarina, Brazil. Restoration Ecology, v. 16, n. 3, p. 444-452, 2008.

SCARIOT, A. et alii. Vegetação e flora. In: RAMBALDI, D. M., OLIVEIRA, D. A. S. (Org.). Fragmentação de ecossistemas: causas, efeitos sobre a biodiversidade $e$ recomendações de políticas públicas. Brasília: MMA, 2003. p. 103-23.

TABARELLI, M., PERES, C. AAbiotic and vertebrate seed dispersal in the Brazilian Atlantic Forest: Implications for Forest regeneration. Biological Conservation, v. 106, p. 165-176, 2002.

VAN DER PIJL, L. Principles of dispersal in higher plants. 2. ed. Berlim: SpringerVerlag, 1972. 162p.

VOLPATO, M. M. L. Regeneração natural em uma floresta secundária no domínio de mata atlântica: uma análise fitossociológica. Viçosa: Universidade Federal de Viçosa, 1994. 123f. (Tese de Doutorado em Ciência Florestal).

Artigo recebido em 25/08/2008 e aprovado em 18/05/2009. 